Int. J. Electrochem. Sci., 11 (2016) $8779-8796$

\title{
Corrosion and 3D crack-propagation Behaviors in Reinforced Concrete Subjected to Bending Load in Simulated Marine Environment
}

\author{
Zuquan Jin ${ }^{1, *}$, Xia Zhao ${ }^{2, *}$,Tiejun Zhao ${ }^{1}$,Li Yang ${ }^{1}$ \\ ${ }^{1}$ College of Civil Engineering, Qingdao Technological University, Qingdao, China \\ ${ }^{2}$ Key laboratory of Marine Environmental Corrosion and Bio-fouling, Institute of Oceanology, \\ Chinese Academy of Science, Qingdao, China \\ *E-mail: jinzuquan@126.com, zhxiakk@163.com
}

doi: $10.20964 / 2016.10 .26$

Received: 13 June 2016 / Accepted: 6 August 2016 / Published: 6 September 2016

The corrosion-cracking behavior of reinforced concrete subjected a sustained bending load and exposed to simulate marine environments was studied. The simulated marine environments include an atmosphere zone, a submerged zone and a tidal zone. The corrosive crack distribution in the inside of a concrete was observed using X-CT nondestructive technology. Results showed that the bending load caused both the corrosion rate of steel bar and the crack propagation inside the concrete to accelerate. These effects become apparent when the load exceeds $50 \%$ of the ultimate load. The negative effect of the bending load on the accelerated corrosion rate of reinforced concrete in the submerged marine environment is even more significant than that in an indoor atmospheric environment. The constant potential accelerate test with embedded auxiliary stainless rebar electrode is not an appropriate accelerated choice to study the corrosion behavior of reinforced concrete in the submerged and tidal zones because the potential accelerates the chloride ion penetration into the concrete, and embedded auxiliary stainless rebar electrode changes the crack direction from the steel bar induced by corrosion.

Keywords: reinforced concrete; potentiostatic acceleration; bending load; X-CT; marine environment

\section{FULL TEXT}

(C) 2016 The Authors. Published by ESG (www.electrochemsci.org). This article is an open access article distributed under the terms and conditions of the Creative Commons Attribution license (http://creativecommons.org/licenses/by/4.0/). 